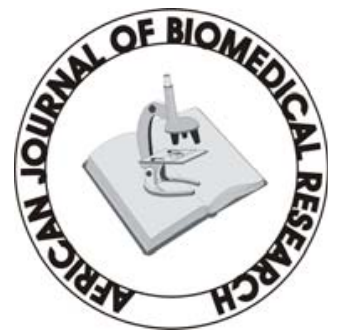

Full-text available at http://www.ajbrui.com http://www.bioline.br/md http://www.ajol.com

Received:

March 2007

Accepted (Revised): April 2007

Published May 2007
Full Length Research Article

\section{A comparative assessment of ribosomal DNA polymorphisms in methicillin resistant Staphylococcus aureus (MRSA) epidemiology}

\author{
O.A. Terry Alli ${ }^{1}$, O.Akinloye, D.A.Rowley ${ }^{\#}$, and Philip D. \\ Butcher *
}

Department of Biomedical Sciences, College of Health Sciences, Ladoke Akintola

University of Technology, Osogbo, Nigeria,

\#School of Biosciences and Health Studies, University of East London, Romford

Road, London E15 4LZ, and

*Department of Medical Microbiology, St. George's Hospital Medical School, Cranmer Terrace, London SW17 ORE, United Kingdom

\section{ABSTRACT}

Chromosomal DNA from 19 strains of methicillin resistant Staphylococcus aureus (MRSA) which included 13 strains from different geographical locations in England and 6 strains from St George's Hospital (SGH), London, with MRSA NCTC 119040 and Oxford S. aureus were digested with the restriction endonucleases, HindIII and HaeIII. Southern blot hybridisation was carried out on the DNA digests transferred onto membrane using radioactive probe prepared from 16S and 23S rRNA from Escherichia coli. The pattern of bands which depended on restriction fragment length polymorphisms was used as a measure of minor genomic variation within the MRSA strains. Phage typing, biotyping, antibiogram, and plasmid profile analysis were also carried out on all the strains for comparison. Four and five different patterns were obtained for HindIII and HaeIII, respectively for representative isolates from different geographical locations in England for that year. Three different patterns were identified among the MRSA strains from SGH, London, using HaeIII. None of the epidemiological markers used in this study gave results that correlated with each other. Ribosomal DNA polymorphisms have proved to be a very useful technique for studying the epidemiology of MRSA in hospitals when used along with other epidemiological markers.

(Afr. J. Biomed. Res. 10: 117 - 125

Keywords: MRSA, rDNA polymorphism, biotyping , phage typing, antibiogram, plasmid profile analysis.

*Address for Correspondence (e-mail): Dr O.A.Terry Alli Phone: +234 (0) 8056586849

Electronic mail address: alliot@hotmail.com

Abstracted by:

African Index Medicus (WHO), CAB Abstracts, Index Copernicus, Global Health Abstracts, Asian Science Index, Index Veterinarius, Bioline International , African Journals online 
African Journal of Biomedical Research, Vol. 10 (2007); 117 - 125

ISSN 1119 - 5096 (C) Ibadan Biomedical Communications Group

\section{INTRODUCTION}

Methicillin resistant Staphylococcus aureus (MRSA) as the name implies is a group of $S$. aureus that are resistant to methicillin - a penicillinase resistant penicillin antibiotic that is used for treatment of infection due to $S$. aureus. S. aureus is an opportunistic pathogen and it is responsible for a mild infection involving the skin like impetigo, osteomyelitis, furuncles or boils, cellulitis and post operative wound infections. This organism is also responsible for serious infections like pneumonia, osteomyelitis, acute endocarditis, pericarditis, cerebritis, and meningitis, to mention a few. MRSA is a nosocomial infection and in recent time it can be acquired in the community (Boyce, 1998). The most important properties of MRSA are the development of resistant to most of the antibiotics that are used in treatment of staphylococcal infections and the fact that that these strains have got propensity to spread within the hospital communities. Community acquired MRSA strains appear more susceptible to several antibiotics, and usually resistant to $\beta$-lactam antibiotics (Boyce, 1998).

MRSA came to limelight in the early 1980s as a major clinical and epidemiological problem in hospitals after the first report in the UK in 1961 (Jevons, 1961) . In a survey of 3051 S. aureus isolates from 25 university hospitals distributed among 15 countries of central and southern Europe (Fluit et al., 2001), MRSA isolates constituted 25\% of all isolates, the highest prevalence was seen in hospitals in Portugal (54\%) and Italy (from 43 to $58 \%$ ), whereas the lowest prevalence was observed in hospitals in Switzerland and the Netherlands (2\%). Between 1999 and 2001, UK had seen general increase in the prevalence of MRSA from $33.4 \%$ in 1999 to $45.4 \%$ in 2001 (Fluit et al., 2001). The incidence of MRSA among the $S$. aureus isolates at University College Hospital, Ibadan, Nigeria in 1989 was generally put at $17 \%$ (Alli and Rotilu, unpublished results). Recent survey of MRSA at a teaching hospital in Ilorin, Nigeria put the incidence of MRSA at 34.7\% (Taiwo et al., 2005).

The gene responsible for methicillin resistance in S. aureus is mecA (Ubukata et al., 1989) with associated mec DNA. This is possible through the Abstracted by:

African Index Medicus (WHO), CAB Abstracts, Index Copernicus, Global Health Abstracts, Asian Science Index, Index Veterinarius, Bioline International , African Journals online introduction of exogenous DNA into its genome and this region has been found to be mobile, is known as staphylococcal chromosomal cassette mec (SSCmec) (Oliveira et al., 2001, Hiramatsu et al., 2001). There are four classes of mec gene complex, of which only classes A (the original clone) and B have been identified in S. aureus; classes $\mathrm{C}$ and $\mathrm{D}$ have been identified in coagulase negative staphylococci (CNS) (Hiramatsu et al., 2001). These classes of SSCmec differ from each other in size and genetic composition (Oliveira et al., 2001, Hiramatsu et al., 2001).

There are many epidemiological markers used for studying the epidemiology of MRSA within a community. These ranges from a traditional method like phage typing (Williams and Rippon, 1952), biotyping (Coia et al., 1990), serotyping (Melo Cristino et al., 1986), to classical methods, which make use of molecular biological techniques (pulse field gel electrophoresis (PFGE)(Wielders et al., 2002), ribotyping(Wielders et al., 2002), restriction fragment analysis of plasmid) such as looking at differences in chromosome and extra-chromosomal element like plasmid. This study was aimed in assessing the value of the detection of rDNA polymorphisms in the genome of $S$. aureus as a typing system in studying the epidemiology of MRSA. This method would be compared with several commonly used epidemiological markers in attempt to distinguish the representative isolates of MRSA from different geographical locations in England, isolated along with some strains from St George's Hospital (SGH), London.

\section{MATERIALS AND METHODS}

Organisms. A total of 20 MRSA strains were used. Fourteen strains of these 20 were obtained from the Staphylococcus Reference Laboratory, Colindale, London, UK; the remaining 6 strains were from St George's Hospital (SGH), London, UK. Details of these strains are provided in Table 1.

Phage typing. Phage typing was performed by the Staphylococcus Reference Laboratory, Central Public Health Laboratory (CPHL), Colindale, London. The standard international set of typing 
phages was used to type all the strains with exception of strains 14 and 15 (control strains).

Antibiograms. Antimicrobial susceptibility was determined by the disc diffusion method on diagnostic sensitivity testing agar containing lysed horse blood ( $5 \% \mathrm{v} / \mathrm{v})$. The following antimicrobial agents were used: gentamicin $(10 \mu \mathrm{g})$, erythromycin $(15 \mu \mathrm{g})$, clindamycin $(2 \mu \mathrm{g})$, tetracycline $(10 \mu \mathrm{g})$, fucidic acid (10 $\mu \mathrm{g})$, rifampicin (2 $\mu \mathrm{g})$ and penicillin (1 unit). The test organism and reference strain were incubated at $37^{\circ} \mathrm{C}$ overnight. The organism was reported as sensitive if the radius of the zone of inhibition was wider than, equal to, or not more than $3 \mathrm{~mm}$ smaller than that observed with the Oxford $S$. aureus and resistant, if there was no zone of inhibition or zone radius measured $2 \mathrm{~mm}$ or less. Methicillin susceptibility was determined on blood agar $(15 \% \mathrm{v} / \mathrm{v})$ with a heavy inoculum obtained from a blood agar plate. The test was incubated at $30^{\circ} \mathrm{C}$ overnight with $10 \mu \mathrm{g} /$ disc of methicillin.

Table 1.

A list of 20 MRSA strains showing location and year of isolation.

\begin{tabular}{llc}
\hline Strain Number & Location & Year of isolation \\
\hline 1 & Windsor & 1986 \\
\hline 2 & Gatwick & 1986 \\
\hline 3 & Liverpool & 1986 \\
\hline 4 & Romford & 1986 \\
\hline 5 & Aylesbury & 1986 \\
\hline 6 & Reading & 1986 \\
\hline 7 & Not known & 1986 \\
\hline 8 & Enfield & 1986 \\
\hline 9 & Nunhead & 1986 \\
\hline 10 & Farnborough Town & 1984 \\
\hline 11 & Exeter & 1986 \\
\hline 12 & Not known & 1986 \\
\hline 13 & Southampton & 1986 \\
\hline 14 & & \\
NCTC11940 & & 1991 \\
\hline 16 & Ward A & 1991 \\
\hline 17 & Ward A & 1991 \\
\hline 18 & Ward B & 1991 \\
\hline 19 & Ward C & 1991 \\
\hline 20 & Ward D & 1991 \\
\hline 21 & OPD & 6571 \\
\hline$S t a n d$ & Wather Oxfor & \\
\hline
\end{tabular}

Strain number 15 was the Oxford S. aureus NCTC 6571 which has not acquired antibiotic resistance.

Biotyping. Biotyping was based on three properties, hydrolysis of Tween 80, urease production, and gentamicin sensitivity. Tween $80(1 \% \mathrm{v} / \mathrm{v})$ was incorporated into nutrient agar (oxoid) and the test organism was spread over an area approximately 1 $\mathrm{cm}$ in diameter and incubated at $37^{\circ} \mathrm{C}$ for about $48 \mathrm{~h}$ . A positive test was denoted by the appearance of a halo of fatty acids around the inoculum.

Urease production was tested in $2 \mathrm{ml}$ volume of peptone water agar containing urea $(2 \% \mathrm{v} / \mathrm{v})$ and phenol red $0.0012 \%(\mathrm{v} / \mathrm{v})$ as an indicator. A heavy inoculum was used. The test was incubated at $37^{\circ} \mathrm{C}$ for 36 to $48 \mathrm{~h}$. A positive test was indicated by a pink colour of the medium. No change in the colour of the medium indicated urease negative strains.

Gentamicin sensitivity results were taken from the antibiogram. The results of biotyping were interpreted as shown in Table 2.

Table 2.

Biotypes of MRSA

Patterns of results forming biotype

\begin{tabular}{lllllll}
\hline Test Biotype & A & B & C & D & E & F \\
\hline Tween 80 hydrolysis & - & - & + & + & + & - \\
\hline Urease & - & + & - & + & + & - \\
\hline Gentamicin & $\mathrm{S}$ & $\mathrm{R}$ & $\mathrm{S}$ & $\mathrm{R}$ & $\mathrm{S}$ & $\mathrm{R}$ \\
\hline$-=$ Negative result & & & & $+=$ Positive result \\
$S=$ Sensitive & & & & $R=$ Resistant
\end{tabular}

Plasmid profile analysis. Plasmid was extracted from each strain following a modification of the Birnboim and Doly procedure (Birnboim and Doly, 1979). Bacteria from $15 \mathrm{ml}$ of an overnight brain heart infusion broth culture were harvested by centrifugation in a $1.8 \mathrm{ml}$ Eppendorf tube in a microfuge for $30 \mathrm{~s}$.

The cell pellets were re-suspended in $100 \mu \mathrm{l}$ of lysis buffer (50 mM glucose, $10 \mathrm{mM}$ EDTA, and 2.5 $\mathrm{mM}$ Tris $\mathrm{HCl}, \mathrm{pH} 8.0$ ) containing $2 \mu \mathrm{l}$ of the stock lysostaphin $(100 \mathrm{mg} / \mathrm{l})$. The sample was first incubated at $37^{\circ} \mathrm{C}$ for $30 \mathrm{~min}$ followed by the addition of $200 \mu \mathrm{l}$ of alkaline sodium dodecyl sulphate - (1\% SDS in $0.2 \mathrm{M} \mathrm{NaOH})$ and the mixture was incubated for additional $10 \mathrm{~min}$ at $37^{\circ} \mathrm{C}$. After $10 \mathrm{~min}$, the lysates were neutralized by the addition of $150 \mu \mathrm{l}$ of 3M sodium acetate, $\mathrm{pH} 4.8$ and mixed. The resultant mixture was chilled on ice for 5 
min and centrifuged for 10 min at room temperature. Four hundred microlitre of the supernatant was removed and transferred to $1.8 \mathrm{ml}$ Eppendorf tube. Phenol-chloroform (1:1, v/v) extraction was carried out on all the samples twice. The resulting upper aqueous phase was then precipitated with equal volume of $100 \%$ ethanol at $-80^{\circ} \mathrm{C}$ overnight. Ethanol was decanted and the DNA pellet was air dried. The DNA was dissolved with TE buffer $(10 \mathrm{mM}$ Tris.HCl pH 8.0; 1 mM EDTA). RNA was removed by digesting the DNA solution with pancreatic RNase $(0.1 \mathrm{mg} / \mathrm{ml})$. The DNA samples were electrophoresed along with $\lambda$ HindIII molecular size marker at $100 \mathrm{~V}$ in $1 \%$ agarose gel and stained with ethidium bromide for photography under UV illumination.

Ribosomal DNA polymorphism analysis. Bacteria from $10 \mathrm{ml}$ of overnight broth culture were centrifuged and the bacterial pellets were lysed in $0.5 \mathrm{ml}$ of TES (Tris HCl pH 8.0, $1 \mathrm{mM}$ EDTA and $0.1 \mathrm{M} \mathrm{NaCl}$ ) containing lysostaphin at a concentration of $1 \mathrm{mg} / \mathrm{ml}$. Phenol-chloroform extraction of the DNA was carried out on all the samples and the DNA precipitated as described in the procedure for plasmid extraction. About $1 \mu \mathrm{g}$ of DNA was digested with HindIII or HaeIII (Invitrogen) at $37^{\circ} \mathrm{C}$ in the presence of reaction buffer following the manufacturer's instructions. The digested DNA was electrophoresed through 1\% agarose gel and Southern blotted (Southern, 1975)onto a hybond membrane. The transferred DNA on the nylon membrane was UV cross-linked using UV transilluminator.

The ${ }^{32} \mathrm{P}$ dCTP rRNA specific cDNA probe was prepared according to Cox et al. method (Cox et al., 1990). Briefly, cDNA was synthesized from Escherichia coli 16S + 23S rRNA (Boehringer Mannheim) in the presence of bovine serum albumin, oligolabelling buffer, random primers, reverse transcriptase, dNTPs and $20 \mu \mathrm{Ci}$ of $\alpha-{ }^{32} \mathrm{P}$ $\mathrm{dCTP}$ in a $50 \mu \mathrm{l}$ volume reaction. The reaction was stopped by adding $5 \mu \mathrm{l}$ of $0.5 \mathrm{M}$ EDTA pH 8.0 and incubated at $65^{\circ} \mathrm{C}$ for $15 \mathrm{~min}$ before $10 \mu \mathrm{l}$ of $2 \mathrm{M}$ $\mathrm{NaOH}$ was added to hydrolyse the rRNA template. The non-incorporated radioactivity was removed by spin column chromatography. Radiolabelled cDNA probe was then used in the hybridisation described below.
The blot was prehybridised in prehybridising solution (6 x SSC, 5 x Deinhardt's solution, 0.5\% SDS) with denatured solution of sonicated non homologous salmon sperm DNA in a hybridization oven set at $65^{\circ} \mathrm{C}$ for $1 \mathrm{~h}$. Thereafter, $\alpha-{ }^{32 \mathrm{P}} \mathrm{dCTP}$ rRNA specific cDNA probe was added and hybridised at $65^{\circ} \mathrm{C}$ for $18 \mathrm{~h}$. The membrane was washed for 45 min with 3 x SSC containing $0.1 \%$ SDS (v/v) and autoradiographed at $-70^{\circ} \mathrm{C}$ using Kodak photographic film.

\section{RESULTS}

The results of the phage typing, biotyping, antibiogram, and plasmid profile analysis are shown in Table 3. Three of the MRSA strains exhibited the same phage typing pattern (85) with three MRSA strains non typable using international set of phages. The 14 remaining strains exhibited variable phage typing patterns including MRSA strains from SGH, London.

Biotyping grouped the 20 MRSA strains into five groups. None of the MRSA strains in this study displayed Tween 80 hydrolysis negative, urease negative along with gentamicin resistance together suggesting group $\mathrm{F}$ strain is a rare occurrence. All the MRSA strains were sensitive to rifampicin and clindamycin. Erythromycin and tetracycline resistance were common among the MRSA strains with eleven of the MRSA strains resistant to penicillin, erythromycin, and tetracycline. Plasmids were not detected in fifteen (71.4\%) of the MRSA strains studied (Figs. 1 and 2). Four of the five MRSA strains that had plasmid DNA had two types of plasmids.

Chromosomal DNA from 20 MRSA strains and Oxford S. aureus was completely digested with HindIII producing complex patterns of many bands on agarose gel electrophoresis (data not shown). These digests were probed with ${ }^{32} \mathrm{P}$ labelled $E$. coli ribosomal cDNA, giving patterns that comprised between five and seven well resolved bands (Fig. 3 and Table 4) with sizes between 2 and $11 \mathrm{~kb}$. The results for strain numbers 3,7 , and 13 were calculated from the repeated experiment. Minor strain differences were discernable, and four different patterns were identified on the basis of the presence or absence of bands and by size differences. The majority of the strains were RFLP2. 
Bands with the following sizes, 4.4, 3.7, and $2.0 \mathrm{~kb}$ strains DNA digested with HindIII. were distinctive common features of the MRSA Table 3.

Phage type, biotype, resistance profile, and plasmid profile analysis of 20 MRSA strains

\begin{tabular}{|c|c|c|c|c|}
\hline Serial Number & Phage type (RTD x 100) & Biotype & Resistance Profile & Plasmid Profile (kb) \\
\hline 1 & 85 & $\mathrm{~A}$ & PENFTM & $2.0,3.0$ \\
\hline 10 & 52/52A/79/80/95/85 & $\mathrm{A}$ & $\begin{array}{ll}\mathrm{PE} & \mathrm{TM} \\
\end{array}$ & - \\
\hline 16 & 29/52/52A/80/85 & $\mathrm{A}$ & $\mathrm{PE} \quad \mathrm{M}$ & - \\
\hline 17 & 29/52/52A/79/80/95/53/83A/85 & $\mathrm{A}$ & $\mathrm{PE} \quad \mathrm{M}$ & - \\
\hline 21 & 29/52/52A/79/80 & $\mathrm{A}$ & $\mathrm{PE} \quad \mathrm{M}$ & - \\
\hline 8 & $84 / 85$ & $\mathrm{~B}$ & $\begin{array}{ll}\mathrm{P} & \mathrm{TMG} \\
\end{array}$ & - \\
\hline 20 & NON TYPABLE & $\mathrm{B}$ & PEN TMG & 2.0 \\
\hline 3 & 29/6/53/75/77/83A & $\mathrm{B}$ & P N FTM & $1.3,1.6$ \\
\hline 19 & 75 & $\mathrm{C}$ & PEN . M & - \\
\hline 4 & 53/83A/84/85 & $\mathrm{C}$ & PE $\quad$ TMG & - \\
\hline 7 & $29 / 54 / 84 / 85$ & $\mathrm{D}$ & PEN TMG & - \\
\hline 11 & 29/52/52A/80/95/81 & $\mathrm{D}$ & $\begin{array}{ll}\text { PEN } & \text { MG } \\
\end{array}$ & - \\
\hline 12 & 53/83A/84/85 & $\mathrm{D}$ & PE $\quad$ TMG & - \\
\hline 2 & 85 & $\mathrm{D}$ & TM & - \\
\hline 5 & 85 & $\mathrm{E}$ & $\mathrm{M}$ & - \\
\hline 6 & NON TYPABLE & $E$ & TM & - \\
\hline 9 & NON TYPABLE & $\mathrm{E}$ & TM & - \\
\hline 13 & $29 / 52$ & $E$ & TM & $1.4,1.9$ \\
\hline 14 & NOT DONE & $\mathrm{E}$ & TM & $1.4,1.9$ \\
\hline 18 & $29 / 52 / 80$ & $E$ & TM & - \\
\hline $\mathrm{P}=$ Penicillin & $\mathrm{T}=$ Tetracycline & & ethicillin & acid \\
\hline
\end{tabular}

Gentamicin

$\mathrm{N}=$ Neomycin $\quad$ RTD $=$ Routine Test Dilution

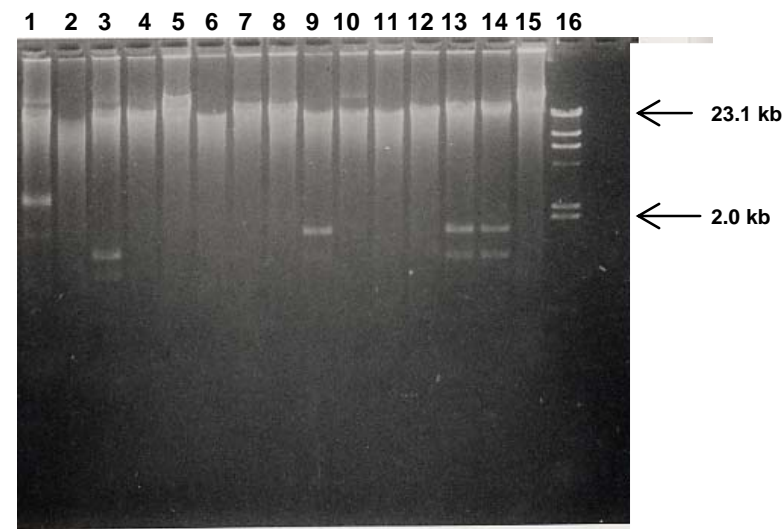

Figure 1.

Electrophoretic mobility of plasmid extracted from MRSA strains from different geographical locations in England on 1\% agarose gel. Lanes 1-13: SN1-13 of the MRSA strains studied as described on Table 1; lane 14: MRSA NCTC 11940; lane 15: Oxford S. aureus; and lane 16: $\lambda$ HindIII molecular size marker.

\section{$\begin{array}{lllllll}1 & 2 & 3 & 4 & 5 & 6 & 7\end{array}$}

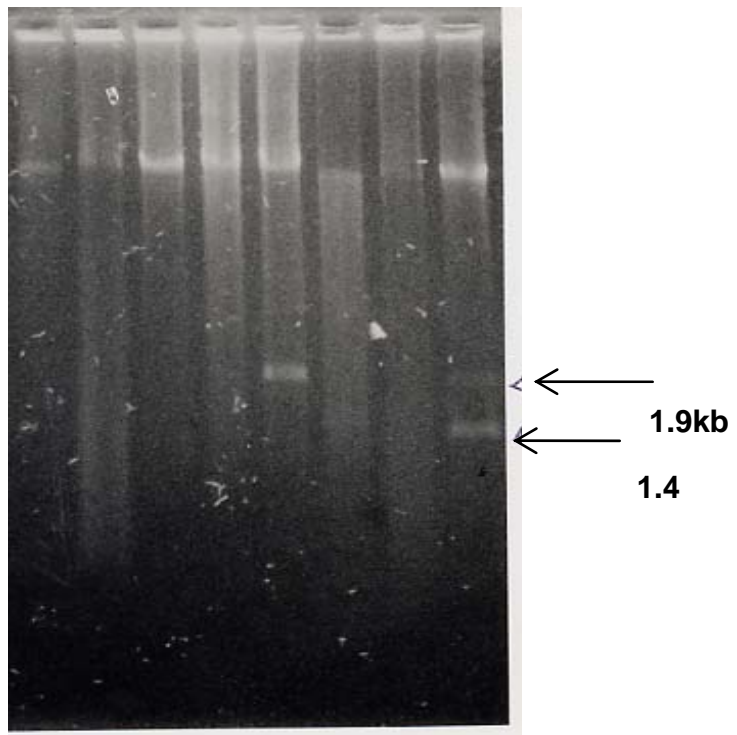

Figure 2

Electrophoretic mobility of plasmid extracted from MRSA strains from SGH, London on $1 \%$ agarose gel. Lanes $1-6$ : SN16-21 of the MRSA strains studied as described on Table 1; 
lane 7: Oxford S. aureus; and lane 8: MRSA NCTC 11940.

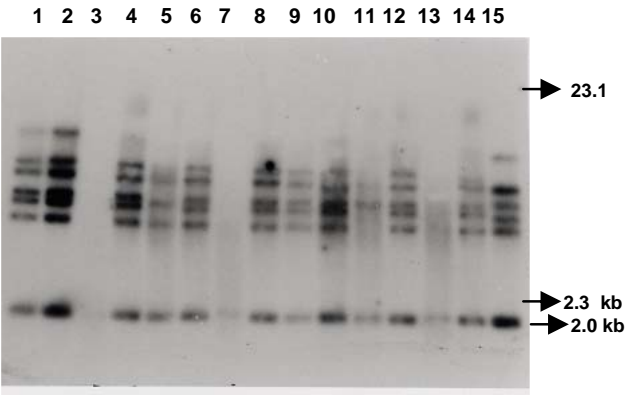

Figure 3.

Hybridisation of ${ }^{32} \mathrm{P}$ labelled ribosomal cDNA from $E$. coli with Southern blotted HindIII restriction fragments of MRSA strains and Oxford $S$. aureus. Lanes $1-13$ : SN1-13 of the MRSA strains studied as described on Table 1; lane 14: MRSA NCTC 11940; and lane 15: Oxford S. aureus.

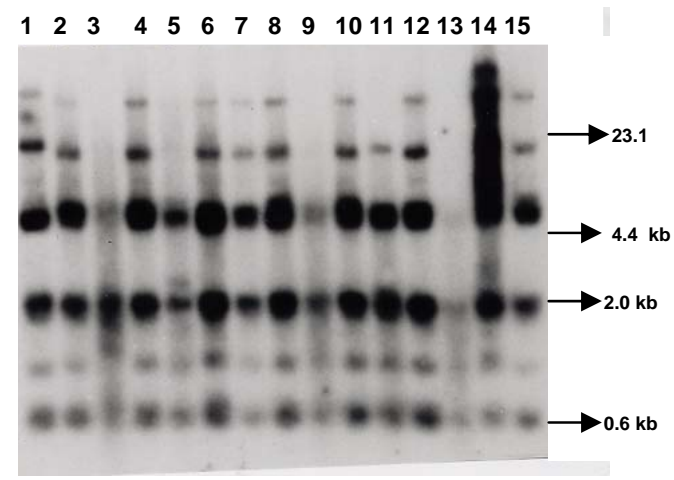

Figure 4.

Hybridisation of ${ }^{32} \mathrm{P}$ labelled ribosomal cDNA from $E$. coli with Southern blotted HaeIII restriction fragments of MRSA strains and Oxford S. aureus. Lanes 1 - 13: SN1-13 of the MRSA strains studied as described on Table 1; lane 14: Oxford $S$. aureus; and lane 15: MRSA NCTC 11940.

The HaeIII digests that were Southern blotted, and hybridised with ${ }^{32} \mathrm{P}$ labelled $E$. coli ribosomal cDNA gave patterns that comprised between four and eight resolved bands with sizes between 0.8 and $52 \mathrm{~kb}$ (Fig. 4 and Table 5). The general features of the rRNA gene fingerprints were also remarkably constant among the MRSA strains. Minor strain differences were observed in using HindIII as a restriction enzyme to digest the genomic DNA, with about five different patterns identified within MRSA strains on the basis of the presence or absence of bands and by size difference. Bands with 5.3, 2.0,
1.0 , and $0.8 \mathrm{~kb}$, were distinctive common features of most of the MRSA strains.

Eight out of the 14 MRSA strains from different geographical locations were typed as RFP2 with HaeIII, while HindIII digest probed with radiolabelled rDNA revealed 9 strains of the 14 as RFLP2. HindIII digest of the chromosomal DNA of MRSA strains study grouped the strains into four distinct groups while the HaeIII grouped the 14 strains into five groups (Table 4). There was a similarity in the grouping of the strains as both HindIII and HaeIII were able to distinguish Oxford $S$. aureus as a different clone from the MRSA strains. Only one banding pattern difference was noticed in the use of these two enzymes. Eight of the 14 MRSA strains were typed in the same way as banding pattern 2 with these two enzymes (Table 6), suggesting that restriction fragment length polymorphism of rDNA has low discriminatory capacity compared to phage typing. There was no correlation between biotyping and ribosomal DNA polymorphisms (Table 6) as exhibited by the MRSA strains studied. None of the epidemiological markers gave results that correlated with each other.

\section{Table 4.}

Estimated sizes of rDNA containing bands in HindIII digests of chromosomal DNA and pattern designations of $S$. aureus isolates

\begin{tabular}{lll}
\hline $\begin{array}{l}\text { Strain } \\
\text { Number }\end{array}$ & Band sizes (kb) & $\begin{array}{l}\text { Pattern } \\
\text { designation }\end{array}$ \\
\hline 1 & $\begin{array}{l}11.0,6.7,6.0,5.0,4.4,3.7, \\
2.0\end{array}$ & RFLP1 \\
\hline 2 & $\begin{array}{l}11.0,6.7,6.0,5.0,4.4,3.7, \\
2.0\end{array}$ & RFLP1 \\
\hline 3 & $6.7,6.0,5.0,4.4,3.7,2.0$ & RFLP2 \\
\hline 4 & $6.7,6.0,5.0,4.4,3.7,2.0$ & RFLP2 \\
\hline 5 & $5.4,4.4,3.7,2.0$ & RFLP3 \\
\hline 6 & $6.7,6.0,5.0,4.4,3.7,2.0$ & RFLP2 \\
\hline 7 & $6.7,6.0,5.0,4.4,3.7,2.0$ & RFLP2 \\
\hline 8 & $6.7,6.0,5.0,4.4,3.7,2.0$ & RFLP2 \\
\hline 9 & $6.7,6.0,5.0,4.4,3.7,2.0$ & RFLP2 \\
\hline 10 & $6.7,6.0,5.0,4.4,3.7,2.0$ & RFLP2 \\
\hline 11 & NOT REPORTED & \\
\hline 12 & $6.7,6.0,5.0,4.4,3.7,2.0$ & RFLP2 \\
\hline 13 & $6.0,5.0,4.4,3.7,2.0$ & RFLP4 \\
\hline 14 & $6.7,6.0,5.0,4.4,3.7,2.0$ & RFLP2 \\
\hline 15 & $11.0,6.0,5.0,4.2,3.7,2.0$ & RFLP5 \\
\hline
\end{tabular}


The results of the SGH, London's isolates showed that three groups were discernible within the 6 strains of MRSA studied using HaeIII digest of the chromosomal DNA that were probed with ${ }^{32} \mathrm{P}$ labelled rDNA (data not shown). Four (SN 16, 17, 18 and 21) out of the 6 strains belonged to the same group with the remaining two strains (SN 19 and 20) different from each other; suggesting one particular clone is in circulation within the hospital.

\section{DISCUSSION}

Previous studies on various bacteria which included Providencia stuartii(Owen et al., 1988) and Bacillus $s p$ (Gottlieb et al., 1985) have demonstrated the value of DNA fingerprints derived from RNA cistrons as a basis for species and possibly strain identification. Since methicillin resistant $S$. aureus is recognised to be of clinical importance, this study was undertaken in order to assess the use of ribosomal DNA polymorphisms in the studying of MRSA epidemiology. This method was compared to other epidemiological markers (Tables 3 and 6).

Plasmid profile analysis appears to be of very low discriminatory capacity in the investigation of MRSA epidemiology because of the non-detection of plasmid in the majority of the MRSA strains (figs 1 and 2). Isolates with low copy number plasmid cannot be reliably detected on agarose gel using the plasmid extraction adopted in this study; loss or gain of a single plasmid in an individual strains can mislead the user of this method into jumping into wrong conclusion about the origin of the clone.

Antibiogram and biotyping can be used together in discriminating or in distinguishing closely related strains. The major advantages of biotyping are the simplicity, quickness, and reproducibility especially with the modified biotyping method used in this study. However, strain discrimination is limited with the use of biotype only. The discrimination capacity of this method could be increased by combining it with antibiogram. The antibiogram on its own cannot be used in monitoring the spread and determination of origin of MRSA within the hospital community because of loss or gain of antibiotic resistance due to loss or gain of plasmid DNA. It is a method worth adopting by Medical Microbiology
Reference Laboratories in developing countries where the cost of applying today molecular biological methods in typing of isolates could be too expensive.

These results show that ribosomal DNA polymorphisms provide a novel method of distinguishing between strains of MRSA as well as ordinary $S$. aureus. The analysis was based on results of using HaeIII for digesting chromosomal DNA from S. aureus, because previous studies have shown that this enzyme and HindIII cut with a relatively high frequency, giving distinctive fragment patterns (Butcher et al., Unpublished results). This present study found that HindIII fingerprints contained four to seven bands, but there was less variation in ribosomal DNA polymorphisms between MRSA strains, even though, majority of them were from different geographical locations of England. It could be that only one particular clone was responsible for most cases of MRSA epidemic at that time in UK hospitals. Ribosomal DNA polymorphisms using HaeIII enzyme have been successfully used in distinguishing MRSA strains from different geographical locations and to some extent MRSA strains from different wards in SGH, London. Examples of this case are SN16 and SN17. SN16 was isolated from a patient in Ward A and SN17 was isolated from a nurse in the same ward. They both had the same antibiotic resistant pattern, belonged to the same biotype A and plasmid DNA was not detected in both of them (Table 3), and on ribosomal DNA polymorphisms revealed they both had similar restriction fragment pattern based on HaeIII digestion of chromosomal DNA. The results showed that the nurse was likely to infect the patient on the ward or both acquired it from the same source but the results of phage typing (Table 3 ) showed about four differences in phage susceptibility which according to the interpretation indicates that the two strains are not related. This implies that phage typing is very superior to other epidemiological markers used in this study in discrimination of MRSA strains. It appears that the high discriminatory nature of phage typing could cast doubt on its continual use because mutation in the cell wall receptor for phage could increase the discriminatory power of the method despite the fact that the organisms originated from the same clone. The non typability of some of 
the MRSA strains is also a big problem facing reference laboratories, although this problem has been reduced to some extent with the introduction of extended and supplementary phages.

SN13 and SN14 are other examples where ribosomal DNA polymorphisms could be used in distinguishing the two strains, both strains had the same antibiogram, plasmid DNA content and they both belonged to biotype $\mathrm{E}$ (Table 3). Ribosomal DNA polymorphisms revealed that the two strains were not related despite the fact that phage typing was not done.

The use of ribosomal DNA polymorphisms as a typing method needs to be strictly standardised and this means it could only be performed by a Reference Laboratory such as Staphylococcus Reference Laboratory, Colindale, UK. It can be performed in hospital laboratories where they have dedicated workers for this particular work who have knowledge of the standardisation and interpretation. Moreover, this would also create uniformity in results, and rapid availability of the results so that necessary action/measures can be instituted by the clinician/hospital infections control team. The results can be made more reproducible or easier to interpret with the use of an ultroscan XL laser densitometer and computer analysis(Owen et al., 1988). The method can also be made less hazardous with the use of non radioactive method of labelling. Application of polymerase chain reactions (PCR) technology can reduce the number of days in carrying out this test from 5 days to 2 days.

The rRNA sequences are highly conserved at the species level (Woese, 1987), which means the DNA fingerprint differences observed in this study were attributed to the occurrence of rRNA cistrons in polymorphic restriction fragments resulting from minor base changes in the HaeIII or HindIII sites as a result of insertions or deletions within the enzyme recognition sites. The degree of polymorphism can further be increased by the use of two or more restriction endonucleases which work under the same conditions e.g. combination of HindIII and HaeIII in the digestion of genomic DNA might increase the polymorphisms within the MRSA strains. Although the low discriminatory tendency of this technique is the reason for being a method of choice when combine with other techniques such as
PFGE. PFGE is known to offer more discriminatory power than ribotyping and it is now the gold standard adopted by many reference laboratories for establishing clonal relationships at the local level. The high discriminatory nature of PFGE makes it difficult to be used alone in studying the epidemics of MRSA at regional level, which means that the technique needs to be combined with a technique that is not highly discriminatory such as ribotyping. Adoption of PFGE and ribotyping (rDNA polymorphisms) were successfully used in studying how mecA gene has disseminated within the $S$. aureus population (Wielders et al., 2002).

In conclusion, we found that rDNA fingerprints generated by a HaeIII digestion of genomic DNA provide a novel means of detecting genomic difference and provide the "fine tuning" discrimination, which may be of value in the in depth analysis of the origins and outbreaks of infection with this organism. The combination of rDNA polymorphism with other epidemiological markers will yield a breadth of epidemiological information, which will provide a clearer picture of the spread of MRSA within the hospital.

\section{Acknowledgements}

We are grateful to Dr R. Marples and members of staff of Staphylococcus Reference Laboratory, Colindale for doing the phage typing, Dr J. Johnson and Mr A Lawson of Department of Medical Microbiology, St George's Hospital, London, UK.

\section{REFERENCES}

Birnboim H.C., Doly J. (1979): A rapid alkaline extraction procedure for screening recombinant plasmid DNA. Nucleic Acids Res 7:1513-23.

Boyce J. M. (1998): Are the epidemiology and microbiology of methicillin-resistant Staphylococcus aureus changing? Jama 279:623-4.

Coia J. E., Thomson-Carter F., Baird, D., Platt, D. J. (1990): Characterisation of methicillin-resistant Staphylococcus aureus by biotyping, immunoblotting and restriction enzyme fragmentation patterns. J Med Microbiol 31:125-32.

Cox N., Johnston J., Szarka Z., Wright D. J., Archard L. C. (1990): Characterization of an rRNA gene-specific cDNA probe: applications in bacterial identification. J. Gen. Microbiol. 136:1639-43.

Fluit A. C., Wielders C. L., Verhoef J., Schmitz F. J. 
(2001): Epidemiology and susceptibility of 3,051 Staphylococcus aureus isolates from 25 university hospitals participating in the European SENTRY study. J. Clin. Microbiol. 39:3727-32.

Gottlieb P., LaFauci G., Rudner R. (1985): Alterations in the number of rRNA operons within the Bacillus subtilis genome. Gene 33:259-68.

Hiramatsu K., Cui L., Kuroda M., Ito T. (2001): The emergence and evolution of methicillin-resistant Staphylococcus aureus. Trends Microbiol. 9:486-93. Jevons M. P. (1961): 'Celbenin' -resistant staphylococci. British Medical Journal:124- 125.

Melo Cristino J. A., Pereira A. T., Afonso F., Naidoo J.N. (1986): Methicillin-resistant Staphylococcus aureus: a 6-month survey in a Lisbon paediatric hospital. J. Hyg. (Lond) 97:265-72.

Oliveira D. C., Tomasz A., de Lencastre H. (2001): The evolution of pandemic clones of methicillin-resistant Staphylococcus aureus: identification of two ancestral genetic backgrounds and the associated mec elements. Microb. Drug Resist. 7:349-61.

Owen R. J., Beck A., Dayal P. A., Dawson C. (1988):

Detection of genomic variation in Providencia stuartii clinical isolates by analysis of DNA restriction fragment length polymorphisms containing rRNA cistrons. J. Clin. Microbiol. 26:2161-6.
Southern E. M. (1975): Detection of specific sequences among DNA fragments separated by gel electrophoresis. J. Mol. Biol. 98:503-17.

Taiwo S. S., Bamidele M., Omonigbehin E. A., Akinsinde K. A., Smith S. I., Onile B. A., Olowe A. O. (2005): Molecular epidemiology of methicillin-resistant Staphylococcus aureus in Ilorin, Nigeria. West Afr. J. Med. 24:100-6.

Ubukata K., Nonoguchi R., Matsuhashi M., Konno M. (1989): Expression and inducibility in Staphylococcus aureus of the mecA gene, which encodes a methicillinresistant S. aureus-specific penicillin-binding protein. J. Bacteriol. 171:2882-5.

Wielders C. L., Fluit A. C., Brisse S., Verhoef J., Schmitz F.J. (2002): mecA gene is widely disseminated in Staphylococcus aureus population. J. Clin. Microbiol. 40:3970-5.

Williams R. E., Rippon J.E. (1952): Bacteriophage typing of Staphylococcus aureus. J. Hyg. (Lond) 50:32053.

Woese C. R. (1987): Bacterial evolution. Microbiol. Rev. 51:221-71. 